\title{
O trabalho de docentes universitários da saúde: situações geradoras de prazer e sofrimento
}

\author{
The work of college health sciences faculty: situations that cause pleasure and pain \\ El trabajo de los profesores universitarios del área de la salud: situaciones que generan \\ placer y sufrimiento
}

\author{
Ana Sofia Resque Gonçalves'; Denise Elvira Pires de Pires ${ }^{I I}$
}

\begin{abstract}
RESUMO: Pesquisa qualitativa, descritiva, que objetivou analisar as situações geradoras de prazer e sofrimento no trabalho de docentes da saúde de uma Universidade da Região Norte do Brasil. A coleta ocorreu por meio de entrevista semiestruturada com 25 docentes de cinco faculdades do Instituto de Ciências da Saúde de uma Universidade Federal do Pará, no município de Belém, entre novembro de 2009 e fevereiro de 2010. A técnica utilizada foi a análise temática de conteúdo. Os resultados mostraram que o prazer advém do gostar da docência, do reconhecimento e dos bons resultados do trabalho realizado. O sofrimento provém da insuficiência da remuneração, da precariedade da infraestrutura e das dificuldades nas relações interpessoais. Conclui que as situações geradoras de prazer e de sofrimento se expressam dialeticamente no processo de trabalho dos docentes universitários da saúde e que gostar do que faz promove satisfação, ainda que as condições de trabalho causem sofrimento. Palavras-Chave: Docente; prazer-sofrimento; satisfação no emprego; saúde do trabalhador.
\end{abstract}

ABSTRACT: This qualitative, descriptive study examined situations that cause pleasure and suffering in the work of health studies faculty at a university in northern Brazil. Data were collected between November 2009 and February 2010, through semi-structured interviews of 25 teachers from five departments of the Institute of Health Sciences, Pará Federal University, Belém, and analyzed using thematic content analysis. The results showed that teachers' pleasure at work derived from: enjoying teaching, gaining recognition for their work, and good results. Suffering at work stemmed from: inadequate pay, lack of equipment, and difficult interpersonal relationships. It was concluded that the situations that lead to pleasure and suffering are expressed dialectically in the work process of healthcare teachers, and that enjoying the profession provides satisfaction even though working conditions may cause suffering.

Keywords: Faculty; pleasure-suffering; job satisfaction; occupational health.

RESUMEN: Estudio descriptivo cualitativo, que tuvo como objetivo analizar las situaciones que generan placer y sufrimiento en el trabajo de los profesores del área de la salud de la Universidad del Norte de Brasil. Los datos fueron recolectados a través de entrevistas semiestructuradas junto a 25 profesores de cinco facultades del Instituto de Ciencias de la Salud de la Universidad Federal de Pará en la ciudad de Belén, entre noviembre de 2009 y febrero de 2010. Se utilizó como técnica el análisis temático de contenido. Los resultados muestran que el placer proviene de gustarle la docencia, del reconocimiento y de los buenos resultados del trabajo realizado. El sufrimiento proviene de la insuficiencia de la remuneración, de la precariedad de la infraestructura y de las dificultades en las relaciones interpersonales. Se concluye que las situaciones que generan placer y sufrimiento se expresan dialécticamente en el proceso del trabajo de los docentes universitarios del área de la salud y que gustarle lo que se hace promueve satisfacción a pesar del sufrimiento causado por las condiciones de trabajo.

Palabras Claves: Docente; placer-sufrimiento; satisfacción en el empleo; salud del trabajador.

\section{INTRODUÇÃO}

O mundo do trabalho sofreu transformações e as características das atividades na educação também mudaram. As novas demandas dos processos laborais educativos têm exigido adequações dos professores às inovações tecnológicas, às constantes atualizações e a excelência profissional. Essa exigência tem refletido na vida pessoal, na qualidade de saúde e na satisfação desses trabalhadores ${ }^{1}$.

O trabalho educativo, em especial na área da saúde, em condições adversas ou em demasia pode comprometer a saúde do professor, causando adoecimento. Ao trabalho do professor também estão associados indi-

'Doutora em Enfermagem, Docente Adjunta da Universidade Federal do Pará, Instituto de Ciências da Saúde, Faculdade de Enfermagem. Belém, Pará, Brasil.E-mail: sofiares@ufpa.br sofiaresque@hotmail.com sofiaresque@gmail.com

IIPós-Doutora, Docente Titular da Universidade Federal de Santa Catarina, Centro de Ciências da Saúde, Departamento de Enfermagem. Florianópolis, Santa Catarina, Brasil. E-mail: piresdp@yahoo.com

IIITrabalho oriundo da tese de doutorado em enfermagem intitulada: Prazer e sofrimento no trabalho de docentes da saúde em Universidade Pública da Região Amazônica - Doutorado Interinstitucional-Universidade Federal do Pará/Universidade Federal de Santa Catarina. Defesa em dezembro de 2010. 
cadores de sofrimento/insatisfação e riscos, mas também diferentes graus de prazer, de acordo com o meio e a forma que a atividade é desempenhada. Os professores buscam alternativas para darem sentido ao trabalho em uma relação dialética de prazer e sofrimento ${ }^{2}$.

No entanto, o estudo das situações geradoras de prazer e de sofrimento no trabalho de docentes universitários constitui-se em uma problemática complexa que ainda necessita ser melhor estudada. Assim, objetivou-se analisar as situações geradoras de prazer e de sofrimento no trabalho de docentes universitários da saúde.

\section{REVISÃo DE LITERATURA}

A atividade docente apresenta uma depreciação crescente em decorrência da redução de investimentos na educação superior, seja dos ambientes de trabalho, da remuneração ou, ainda, do reconhecimento social. $\mathrm{O}$ resultado disso tudo, invariavelmente, acentua efeitos perversos de desgaste físico e psicológico, absenteísmo e, até mesmo, abandono da profissão docente ${ }^{3}$.

A tendência do nível de satisfação profissional dos educadores está relacionada à manifestação de vivências afetivas que o professor experimenta no desenvolvimento de sua atuação ${ }^{4}$.

A prática docente como um trabalho dotado de intensificação das relações interpessoais mobiliza um sofrimento que é intrínseco à construção do vínculo didático, movido pela situação de ensino. $\mathrm{O}$ trabalho do professor implica uma exposição no nível relacional. A demanda afetiva com os alunos pode ser intensa, o que pode desencadear uma grande tensão $0^{5}$.

As produções científicas ${ }^{3-5}$ revelam que o número de casos de estresse e da síndrome da desistência (burnout) entre os docentes, associados ou não a outras patologias, tem crescido significativamente.

\section{Metodologia}

Pesquisa qualitativa, descritiva, realizada na Região Norte do Brasil, no município de Belém, Estado do ParálII, com 25 docentes de cinco faculdades do Instituto de Ciências da Saúde de uma Universidade Pública Federal.

As entrevistas semiestruturadas ocorreram entre novembro de 2009 e fevereiro de 2010 com sete professores da faculdade de enfermagem (E), três da medicina $(\mathrm{M})$, cinco da farmácia $(\mathrm{F})$, cinco da nutrição $(\mathrm{N})$ e cinco da odontologia $(\mathrm{O})$, selecionados pelos critérios de intencionalidade e conveniência. Os relatos foram identificados com a letra inicial da profissão e ordem de ocorrência de cada entrevista. Os dados foram suficientes pelo critério de saturação. $\mathrm{O}$ estudo atendeu aos critérios de Pesquisa com Seres Humanos ${ }^{6}$, foi submetido ao Comitê de Ética da Universidade Federal Pará e aprovado sob o parecer n 222/08.
A técnica de análise de conteúdo temática ${ }^{7}$ compôs duas macrocategorias: situações geradoras de prazer no trabalho docente e situações geradoras de sofrimento no trabalho docente.

\section{Resultados e Discussão}

\section{Caracterização dos participantes}

A análise descritiva permitiu os seguintes resultados: entre os 25 docentes, o nítido predomínio de mulheres (19/76\%) revela que é na docência universitária que a mulher tem se destacado, contrariando os dados do Censo da Educação Superior ${ }^{8}$ que apontam mais homens lecionando no ensino superior no Brasil.

No que tange à faixa etária, a média foi entre 41 e 60 anos de idade, compondo um dos grupos ocupacionais dos mais idosos. No Censo ${ }^{8}$ a média foi de 35 anos de idade. Esse resultado pode ser explicado pela quantidade de tempo de preparação para o ingresso na ocupação (doutorado), bem como pela manutenção do trabalho até uma idade, em média, mais avançada que em outras categorias?

O tempo de trabalho variou entre 1 a 36 anos, com diversos professores em vias de aposentadoria. Em torno de 24 (96\%) dos professores, eram efetivos, 12 (48\%) lecionavam na graduação e 13 (52\%) na graduação e pós-graduação. Todos cursaram algum tipo de pós-graduação, consistindo em 12 (48\%) mestres, 9 (36\%) doutores e 4 (16\%) especialistas. O predomínio de mestres contraria o Censo ${ }^{8}$, que aponta $51,4 \%$ dos docentes, em exercício na rede pública de educação superior do Brasil, com doutorado.

\section{Situações geradoras de prazer no trabalho docente}

As situações mais significativas possibilitaram a formulação de quatro subcategorias que por ordem de importância, são explicitadas a seguir.

\section{Gostar da docência}

O trabalho do docente da saúde é dotado de componentes positivos, carregados de significados o que pode levar ao prazer no trabalho. O docente ao gostar do que faz, sente-se satisfeito.

Oprazer de estar fazendo alguma coisa que eu gosto de fazer, para mim isso é muito importante. (F2)

Eu gosto do que eu faço! Eu sempre me identifiquei com essa área [...], então eu trabalho na área que eu gosto. (E1)

A satisfação pessoal e profissional, a identificação com a atividade de ensinar e o tempo de experiência na atividade de professor podem significar, maior estado de empoderamento. A natureza do trabalho e até a vivência de cada indivíduo para com o labor são fatores que influenciam a satisfação profissiona ${ }^{10}$. 
Gostar do que faz é tão importante que supera a sobrecarga, o excesso de atividade e de demandas de trabalho.

Eu tenho uma carga horária muito pesada. Mas, não tem insatisfação não [...]. Porque eu gosto do que eu faço. [...] se fosse em outra situação que eu não gostasse, porque isso aqui é penoso. Mas, como eu gosto do que eu faço, isso não se torna um motivo pra insatisfação. Então eu me sinto assim [satisfeita]. (F3)

gostar do que faz se apresenta como um ponto revigorante no processo de trabalho docente, uma vez que os docentes se sentem responsáveis pela realização da tarefa e a assumem, mesmo considerando esse trabalho penoso.

As dimensões que estruturam o contexto do trabalho docente também causam bem ao corpo, à mente e às relações sociais. As manifestações de prazer são reconhecidas por meio da gratificação, da realização, do reconhecimento, da liberdade e da valorização no trabalho, constituindo-se em indicadores de saúde no trabalho'.

As peculiaridades do ensino em saúde exigem uma relação complexa entre professor aluno e a pessoa do paciente. Esta conformação faz com que a satisfação com a docência seja atribuída ao fato de os mesmo sentir que está contribuindo para formar profissionais que serão úteis para a sociedade.

Eu conseguiria visualizá-los futuramente, poderiam ser grandes profissionais, [...] dentro do que eles se propõem. Eu percebo [...] um aluno estimulado e dedicado ao curso que ele quer. (F3)

O papel do professor na formação de novos cidadãos e profissionais é uma contribuição socialmente reconhecida. $O$ professor, ao reconhecer o seu papel central na sociedade, sente-se responsável pelo preparo do cidadão para a vida. Esse preparo, na realidade, deve ser realizado com alegria, esperança, convicção de que a mudança é possível ${ }^{11}$.

\section{Relações satisfatórias entre professor e aluno}

A interação docente-discente foi saudável e geradora de alto nível de satisfação.

Tenho uma satisfação muito grande na relação com os alunos, muito boa, muito prazerosa, [...] de muita satisfação mesmo. (E3)

Com os alunos, em geral, é muito boa a relação. [...] chegam aqui muito jovens, e de alguma forma, [...] te procuram para aconselhamento, para essas coisas [...] $o$ aluno te considera muito. (F2)

A relação aluno-professor é representada como um fator que influencia nos aspectos benéficos do trabalho, onde o prazer é evidenciado não somente no compromisso, na construção do conhecimento, mas no interesse e aprendizado demonstrados pelos alunos.
Eu vejo uma ressonância positiva dos alunos, ou seja, quando eles estão entendendo o que estou falando $e$ estão interessados, estão aprendendo, isso me deixa muito satisfeito. (F5)

O professor é

o sujeito social que, ao exercer a profissão, constrói elos entre educação e mundo, vida e escola, saber vivido pelo aluno e conhecimentos a serem apreendidos nos tempos e espaços da instituição de ensino ${ }^{12: 1}$.

A relação estudante-professor sofre influência da cultura que traceja o viver cotidiano, as práticas individuais e as coletivas. A docência, como função voltada para a transformação social ${ }^{13}$, necessita de algo mais do que a sensação de utilidade social, talvez seja necessário a promoção de aspectos essenciais que gerem prazer no trabalho².

\section{Reconhecimento do trabalho realizado}

É um fator que influencia a satisfação na relação ensino/aprendizagem, onde o prazer é evidenciado pelo agradecimento, pelo respeito à capacidade criativa que exercem e, principalmente, pelo reconhecimento dos alunos.

A satisfação com o aluno que você vê retribuir. [...] no final de cada semestre tem turmas que homenageiam a gente, que gostam do nosso trabalho. Isso é uma satisfação que não tem preço. É saber que se está dentro de uma instituição que, de certa forma, acredita na gente. (F1)

O que me deixa muito satisfeita é o agradecimento dos alunos. É a resposta dos meus atos. (N1)

O reconhecimento do trabalho, pelos alunos, pelos colegas. (O4)

Os professores se sentem realizados quando têm o reconhecimento das pessoas para as quais prestam seus serviços ${ }^{14,15}$. $O$ reconhecimento é essencial e decisivo para "quem mobiliza sua subjetividade no trabalho" ${ }^{16: 34}$. O reconhecimento do trabalho, ou mesmo da obra, pode depois ser reconduzido pelo

sujeito ao plano da construção de sua identidade e isso se traduz afetivamente por um sentimento de alivio, de prazer, às vezes de leveza d'alma ou até de elevação. $\bigcirc$ trabalho se inscreve então na dinâmica da realização do ego ${ }^{16: 34}$.

Quando havia reconhecimento do trabalho, por parte da comunidade acadêmica (alunos, colegas) e também da instituição e dos usuários, eram gerados sentimentos positivos, vitalidade e satisfação no trabalho, ou seja, o reconhecimento contribui para a realização do trabalhador e para a produção da saúde ${ }^{1}$.

A relação dos professores com alunos e colegas, na instituição na qual realizam suas atividades, é importante por ser nesse espaço que se estabelecem os fatores que interagem diretamente nos sentimentos de prazer. 


\section{Visualização do produto do trabalho}

O prazer no processo de trabalho pode advir também da visualização do produto do trabalho, perceber os bons resultados obtidos. Os participantes indicaram que realizar um trabalho que é útil para a sociedade, contribui para a satisfação do trabalhador.

As pesquisas que eu desenvolvi me deram uma satisfação pessoal muito grande, porque eu fiz boas publicações, eu tenho reconhecimento nacional graças à dedicação a essas pesquisas. (F4)

Dá satisfação quando se vêo resultado do trabalho.

Quando eu vejo alguma coisa sendo produzida, quando oriento um TCC, que provavelmente a gente vai publicar como livro, isso eu acho que é a maior satisfação. (N5)

Estes resultados propiciaram a compreensão de que o trabalho é um processo dinâmico, que tem uma dimensão subjetiva e que envolve determinações e constrangimentos macroestruturais que se refletem no prazer e na saúde do trabalhador/docente ${ }^{2,3}$.

A maior fonte de satisfação, no trabalho do docente da saúde, concentra-se no fato de que as suas intervenções auxiliam na manutenção da vida humana ${ }^{17,18}$.

A docência é a oportunidade de participar da vida de um ser humano, porque não é só você ensinar, [...]. Para fazer o cuidado você tem preocupação de manter aquela vida [...]. (E7)

Eu posso ver a recuperação do estado nutricional do paciente, para mim é sensacional [...] é muito dolorido quando você perde um paciente. [...] a grande satisfação é eu ver que a nutrição tem importância fundamental na qualidade de vida do indivíduo. (N3)

O trabalho do docente universitário da saúde vincula respeito e responsabilidade pela manutenção da vida do outro ${ }^{18}$ e não se prende apenas no produzir, como ditam as exigências profissionais por qualificação e metas de produtividade nas publicações, orientações e participação na comunidade científica ${ }^{5}$. Os que trabalham investem esforços de todo modo, então "é justo que essa contribuição seja reconhecida" 16:34.

Os resultados do trabalho, uma vez visualizados e reconhecidos, podem oportunizar ao professor o alcance do sentido de sua relação para com o trabalho e então gozar os benefícios desse reconhecimento experimentando prazer na atividade docente.

\section{Situações geradoras de sofrimento no trabalho}

As mais significativas permitiram formular três subcategorias, analisadas a seguir.

\section{Insuficiência da remuneração}

Esta subcategoria aparece como um fator importante no processo de trabalho, capaz de gerar sofrimento, uma vez que o docente está engajado na construção do futuro profissional de saúde e se sente desvalorizado quanto a esse aspecto. Os professores de quase todas as faculdades do estudo estavam insatisfeitos com a desvalorização salarial.

É satisfatório em todos os itens menos na questão salarial. [...] ]você tem uma carga de DE [dedicação exclusiva] e fica bitolada a um salário X, enquanto que, quando você não é $\mathrm{DE}$, você pode ter múltiplas outras alternativas, [...] [com maior ganho financeiro e tudo mais]. (F1)

[...] o docente, ele é muito mal remunerado por tudo o que ele faz. [...], somos DE, fazemos pesquisa, ensino e extensão, numa carga horária altíssima, [...] fazendo andar os projetos de pesquisa [...] tendo vários alunos sob orientação. (M3)

O médico do hospital universitário com 40h semanais, com mestrado, ganha mais do que um docente com o meu perfil que tem doutorado e é DE. [...] não que eu ache que o profissional... técnico tem que ganhar bem mesmo para segurar as pontas, nós temos que segurar..., com um salário defasado....isso desestimula. (M3)

O salário contém numerosas significações: primeiramente concretas (sustentar a família, pagar as dívidas e outros), mas também abstratas, na medida em que

o salário contém sonhos, fantasias e projetos de realizações possíveis. No caso inverso, o salário pode veicular todas as significações negativas que implicam as limitações materiais que ele impõe $e^{19: 50}$.

Algumas declarações demonstraram sentimentos de injustiça, ao reportarem-se à desigualdade salarial em relação às outras áreas e entre professores (efetivo e temporário) e indignação com o salário. A injustiça foi o aspecto mais significativo relacionado ao sofrimento com o salário, segundo critérios de frequência e intensidade adotados na análise do discurso dos participantes:

[...] é muito ruim, o salário de um professor substituto, na Universidade Federal, de 40h, é miserável, um pedreiro ganha mais. (E3)

[...] saúde e educação são os salários mais baixos. [...] vê a comparaçãa com os salários do setor jurídico, $e$ que são belos salários! (O2)

O salário [...] me deixa muito insatisfeita [...], eu comparo o salário do professor, Ministério da Educação, com o salário da saúde, Evandro Chagas e outros, eles têm praticamente um quarto do nosso trabalho e ganham mais do que a gente! (M1)

Eu acho que é uma exigência e responsabilidade muito grande que a gente atua, saúde e educação. [...], são as duas áreas prioritárias, mas as menos valorizadas, a educação muito mais que a saúde, então isso me deixa muito insatisfeita. (M1)

Determinados participantes referiram que não sobreviveriam só da renda salarial de docente ou de 
profissional da saúde e que dificilmente o professor seria só professor:

[...] a minha principal fonte de renda não é aqui na universidade. [...] eu tenho outra fonte de renda. Se eu fosse viver só com o salário da universidade, [...] ficaria difícil, complicado. [...] há uma defasagem no salário, deveria ser um pouco melhor. (F5)

Os aspectos negativos presentes na organização do trabalho atuam como componentes importantes no processo de sofrimento dos docentes universitários da saúde, vindo a ocasionar desgaste, envelhecimento e doenças somáticas ${ }^{2}$.

\section{Precariedade da infraestrutura}

As dificuldades inerentes à infraestrutura também têm importância no sofrimento dos docentes universitários da saúde. Déficits e inadequações dificultam a realização de atividades educativas e aumentam as cargas de trabalho. Destacam-se, nesta subcategoria, a falta de materiais, a falta de laboratórios e a falta de apoio da instituição, como relatos de sofrimento:

\section{É [...] [falta de] infraestrutura e apoio a várias ativi- dades. (M2)}

É [...] não ter um laboratório [...] adequado, para fazer tudo que eu imagino. (N4)

O microscópio para nós é muito importante. [...] são pouquíssimos e não tem quem faça manutenção. [...]. Se quebrar um ar condicionado [...] você tem que tirar do bolso para consertar, não existe verba disponível para isso. (F5)

Agora ela [a Universidade] precisa nos ajudar na questão do [...] livro didático. Quando você precisa realmente daquele suporte bibliográfico você tem que ter uma despesa extra. E isso acaba complicando [...] a nossa insatisfação. (E7)

A escassez de recursos materiais, excesso de burocracia e falta de apoio técnico pedagógico, por parte das instâncias superiores do sistema educacional, atuam como fonte de sofrimento para os docentes ${ }^{20}$.

Em relação à organização do trabalho na universidade, havia problemas com a segurança dos edifícios, especialmente contra incêndios, assaltos e outros, além de carência nas instalações sanitárias, as quais repercutiam na saúde dos professores.

A questão das instalações físicas, por exemplo, eu sou hipertensa, dou aula à noite, aqui, não tem água para eu tomar [...] se quiser tomar um remédio [...] eu não tomo o remédio [...], se quiser urinar, eu tenho que aguentar até voltar para casa. A gente até usa essas instalações, mas são deploráveis, [...] muito vergonhoso. (E2)

O que mais me angustia e me prejudica é quando vou para a sala de aula, é um ambiente totalmente insalubre [...]. Então eu já chego chateada. (E6)
O descaso com a educação no cenário nacional se reflete nas condições de trabalho dos docentes 5 e, por conseguinte, estes tendem a criar estratégias para lidar com a imprevisibilidade, com a precariedade das condições em que realizam a atividade de ensino na universidade e com o sofrimento.

Se eu quero [...] fazer uma dinâmica mais diferenciada, tenho que investir nesse processo e levar esse acadêmico para fora da academia, que eu penso que é bem mais produtivo para ele se inserir na realidade. (E6)

E lá [na universidade] não se dispõe minimamente de giz, eu tenho que comprar a minha caneta, o retroprojetor não existe, não temos salas de aula, nós temos que dividir com a medicina, com a odontologia e com a farmácia [...]. (E6)

Os trabalhadores utilizam sua iniciativa, inventividade e cooperação para preencher e ultrapassar as inconveniências, incoerências e impossibilidades práticas do ambiente e da organização prescrita do trabalho².

Comprar materiais didáticos, para assumir as obrigações docentes, põe em relevo a luta pelos direitos sociais até hoje marcada pelo descaso do Estado ${ }^{1}$.

Para um trabalho enriquecedor e prazeroso, é imprescindível que os docentes tenham liberdade para criar e condições para realizar o seu trabalho. Quando isso não ocorre, surge o sofrimento com possibilidade de adoecimento físico e/ou mental.

\section{Problemas nas relações interpessoais}

Destacam-se a superficialidade, a competitividade e a falta de diálogo.

A relação que a gente tem, acaba sendo [...] fria. [...] não se aprofunda, é superficial. Os encontros são para fazer calendário acadêmico [...]. Quem vai dar aula tal dia e tal hora, sem muito avanço no sentido da discussão daquele conteúdo, [...] [não se trabalha para] adequar um conteúdo com outro da outra disciplina, integrar realmente. (E7)

O problema maior é a competitividade que tem entre os docentes, infelizmente isso é uma verdade [...]. As pessoas querem pegar o lugar do outro que já está pronto. As pessoas que já têm anos, aí o outro novo chega, já está achando que pode ficar naquele lugar, quando ele tem que galgar o lugar. Então me deixa muito insatisfeita. (N3)

As relações sociais conflituosas podem afetar a saúde, aumentando tanto as cargas de trabalho quanto o desgaste físico e mental ${ }^{3,5}$.

As situações de sofrimento eram expressas pelos sentimentos de angústia, estresse e desesperança. Identificaram-se, também, problema gerencial e administrativo, carência de professores e excesso de trabalho, falta de qualificação para as demandas do trabalho e jornadas extenuantes interferindo no desempenho do trabalho, na vida pessoal, no bem-estar e na saúde ${ }^{3,5}$, tornando o trabalho cansativo e desgastante. 
As vivências de sofrimento não significaram, necessariamente, adoecer, mas poderiam contribuir para o adoecimento. Os participantes queixaram-se da desvalorização do magistério, refletida na remuneração salarial insuficiente, na insuficiência de recursos humanos e materiais e nas condições em que hoje é realizado o trabalho docente na universidade ${ }^{21}$.

O contexto do trabalho influencia o prazer e o sofrimento, em três dimensões: organização, condições e relações socioprofissionais, onde o docente vivencia o sentido do trabalho objetiva e subjetivamente ${ }^{1}$.

\section{Conclusão}

As situações geradoras de prazer no trabalho dos docentes da saúde revelaram que fazer o que gosta, interagir com o aluno e sentir que o seu trabalho contribui para formar cidadãos e profissionais necessários à sociedade foram elementos importantes à medida que permitiam o reconhecimento social na atividade.

As situações geradoras de sofrimento mostraram que a organização, as condições de trabalho e os problemas nas relações interpessoais interferiam na vida pessoal, no bem-estar e na saúde dos docentes.

As situações geradoras de prazer e de sofrimento se expressam dialeticamente no processo de trabalho, e o gostar do que faz promove satisfação, ainda que as condições de trabalho causem sofrimento aos docentes universitários da saúde. Foi evidenciado que eles reconhecem uma dualidade conflituosa entre sofrimento e prazer no trabalho e demonstram preocupação em encontrar motivos e buscar propostas que minimizem o sofrimento e potencializem o prazer.

As limitações deste estudo consistiram na recusa dos médicos em participar, por falta de tempo, o que reduziu o número dessa categoria e a utilização de único campo de pesquisa.

Espera-se que a adequação das condições e da organização do trabalho dos docentes se mostrem primordiais no cenário das universidades brasileiras e, consequentemente, promovam saúde, qualidade de vida e prazer aos docentes universitários da saúde.

\section{REFERÊNCIAS}

1.Freitas LG, Facas EP. Vivências de prazer-sofrimento no contexto de trabalho dos professores. Estud Pesqui Psicol. 2013; 13 (1): 7-26.

2.Dejours C, Abdoucheli E, Jayet C. Psicodinâmica do trabalho: contribuições da escola dejouriana à análise da relação prazer, sofrimento e trabalho. São Paulo: Atlas; 2011.
3.Cruz, RM; Lemos, JC; Welter, MM; Guisso, L. Saúde docente, condições e carga de trabalho. Revista Electrónica de Investigación y Docencia (REID). 2010; 4, 147-60.

4.Folle A, Lemos CAF, Nascimento JV, Both J, Farias GO. Carreira no magistério público e nível de qualidade de vida no trabalho docente em educação física. Motriz. 2008; $14: 210-21$

5.Codo W. Educação: carinho e trabalho. 3ํe ed. Petrópolis (RJ): Vozes; 2002.

6.Conselho Nacional de Saúde (Br). Resolução n⿳o 466/2012. Aprova as diretrizes e normas regulamentadoras de pesquisas envolvendo seres humanos. Brasília (DF): CNS; 2012.

7.Bardin L. Análise de conteúdo. Tradução de Luís Antero Reto e Augusto Pinheiro. São Paulo: Edições 70/ Livraria Martins Fontes; 2009.

8.Instituto Nacional de Estudos e Pesquisas Educacionais Anísio Teixeira (Br). Censo da educação superior 2012: resumo técnico. Brasília (DF): INEP; 2014.

9.Coradini OL. Os professores universitários como categoria social. UFRGS. Colóquio saber e poder. Focus, Unicamp. 10/2008.

10.Versa GLGS, Matsuda LM. Satisfação profissional da equipe de enfermagem intensivista de um hospital de ensino. Rev enferm UERJ. 2014; 22: 409-15.

11.Freire P. Pedagogia da autonomia: saberes necessários à prática educativa. São Paulo: Paz e Tera; 2011.

12.Correia W. Por que me tornei professor? [site de internet]. Recanto das letras. [citado em 30 jan 2014]. Disponível em: http://www.recantodasletras.uol.com.br 13.Pinhel I, Kurcgant P. Reflexões sobre competência docente no ensino de enfermagem. Rev esc enferm USP. 2007; 41: 711-6.

14.Carlotto MS. Síndrome de Burnout e características de cargo em professores universitários. Psicologia: Organizações e Trabalho. 2004; 4: 145-62.

15.Martins JT, Robazzi MLCC. Implementação de um currículo com mudança radical: sentimentos de prazer e sofrimento. Rev Cogitare Enferm. 2005; 10: 29-35.

16.Dejours C. A banalização da injustiça social. 2a ed. Rio de Janeiro: Fundação Getúlio Vargas; 1999.

17.Batista KM, Bianchi ERF. Estresse do enfermeiro em unidade de emergência. Rev Latino-Am Enfermagem. 2006; 4: 534-9.

18.Piexak DR; Backes DS; Backes MTS; Santos SSC; Gautério DP; Barlem JGT. Percepção de docentes de enfermagem acerca do ambiente no cuidado ao ser humano. Rev enferm UERJ. 2014; 22: 489-93.

19.Dejours C. A loucura do trabalho: estudo de psicopatologia do trabalho. 5a ed. São Paulo: Cortez/Oboré; 2009.

20.Lapo FR, Bueno BO. Professores, desencanto com a profissão e abandono do magistério. Cadernos de Pesquisa. 2003; 118: 65-88.

21.Plan stratégique Université Cheikh Anta Diop de Dakar - UCAD - 2011-2016. Dakar: UCAD; 2011. 